\title{
Influência do número de folíolos e nós no enraizamento de estacas semilenhosas de cipó-de-são-joão(1)
}

\author{
MARÍLIA MILANI(2)*; WILLIAN HEINTZE(2); GILMAR SCHAFER(2) e PAULO VITOR DUTRA DE SOUZA(2)
}

\begin{abstract}
RESUMO
O cipó-de-são-joão (Pyrostegia venusta (Ker-Gawl.) Miers) é uma trepadeira semilenhosa, vigorosa, nativa, com ocorrência em todos os biomas brasileiros e com potencial ornamental. Informações técnicas sobre a propagação desta espécie irão contribuir para a produção de mudas e com isso, o seu maior uso no paisagismo. O objetivo do trabalho foi avaliar a influência do número de folíolos e nós no enraizamento de estacas semilenhosas de cipó-de-são-joão. O experimento foi conduzido sob condições de câmara de nebulização intermitente. O delineamento experimental utilizado foi de blocos casualizados em fatorial $2 \times 3$, sendo respectivamente estacas com um ou dois nós, e zero, um ou dois folíolos. Utilizaram-se quatro repetições com parcelas experimentais constituídas por 12 estacas acondicionadas em substrato de casca de arroz carbonizada, em bandejas de poliestireno expandido com 72 células. Avaliou-se aos 84 dias: o percentual de estacas enraizadas; o comprimento de brotações, a massa seca de brotações, e, por estaca enraizada, a média de: número de raízes - de primeira ordem; comprimento máximo de cada raiz de primeira ordem, volume e a massa seca de raízes. Observou-se que estacas com dois folíolos possibilitaram $66 \%$ de enraizamento, maior comprimento e massa seca de brotações. A maior qualidade do sistema radicular ocorre com estacas com dois folíolos e dois nós. A propagação de cipó-de-são-joão é eficiente através do uso de estacas semilenhosas, contendo dois nós e dois folíolos, mantidas em casa de vegetação sob nebulização intermitente.
\end{abstract}

Palavras-chave: Pyrostegia venusta, estaquia, produção de mudas, paisagismo.

\begin{abstract}
Influence of leaf number and nodes on the rooting of semiwoody cuttings of flame vine

The flame vine (Pyrostegia venusta (Ker-Gawl.) Miers) is a semihardwood vine, vigorous, native, native, occurring in all Brazilian biomes and ornamental potential. Technical information about the propagation of this species will contribute to the production of seedlings and with that, their greatest use in landscaping. This study aimed to evaluate the influence of the number of leaves and nodes in rooting intermediate flame vine. The experiment was conducted under conditions of intermittent mist. The experimental design was a randomized block in factorial $2 \times 3$, being respectively cuttings with one or two nodes, and zero, one or two leaflets. We used four replicates with plots consisting of 12 cuttings placed in substrate of rice hulls in polystyrene trays with 72 cells. We evaluated at 84 days the porcentage of rooted cuttings, length of shoots, dry weight of shoots and, per cutting, average: number of roots - first order; maximum length of each root of the first order, volume and dry weight of roots. It was observed that cuttings with two leaflets enabled $66 \%$ of rooting, greater length and dry mass of shoots. The higher quality of the root system occurs with stakes with two leaflets and two nodes. The spread of flame vine is efficient with semi-hardwood cuttings with two nodes and two leaflets, kept in a greenhouse under intermittent mist.
\end{abstract}

Keywords: Pyrostegia venusta, cuttings, scion production, landscaping.

\section{INTRODUÇÃO}

O cipó-de-são-joão (Pyrostegia venusta (Ker-Gawl.) Miers) é uma trepadeira semilenhosa, nativa e com ocorrência em todos os biomas brasileiros (LOHMANN, 2015) de ramagem densa, encontrada com frequência dispersa em campos, revestindo barrancos, margens de estradas e cercas de pastagens. O nome é alusivo ao seu constante uso na decoração das festividades de São João de norte a sul de todo o País. É uma espécie com potencial ornamental, sendo indicada para coroamento de muros, grades e pergolados e a sua multiplicação pode ser feita por sementes ou por estacas (LORENZI e SOUZA, 1999).

A estaquia explora a possibilidade de as plantas regenerarem raízes a partir de um segmento de ramo, ou de um segmento de raízes (FACHINELLO et al., 2005; HARTMANN et al., 2002). É um método de propagação muito utilizado, sendo sua viabilidade dependente da capacidade de formação de raízes adventícias de cada espécie, da qualidade do sistema radicular formado e do desenvolvimento posterior da planta no seu local definitivo (FACHINELLO et al., 1995).

A presença de folha, por ser fonte de auxina, é um importante fator na promoção do enraizamento de estacas de diversas espécies (OSTERC e STAMPAR, 2011; UBEDA-TOMÁS et al., 2012; VIGNOLO et al., 2014). No entanto, em alguns casos, o número de folhas nas estacas pode prejudicar o enraizamento, devido à perda de água

\footnotetext{
(1) Recebido em 09/07/2015 e aceito em 20/10/2015.

(2) Universidade Federal do Rio Grande do Sul (UFRGS), Departamento de Horticultura e Silvicultura, Porto Alegre-RS, Brasil. *Autor correspondente: mariliakmilani@gmail.com.
} 
por transpiração e à presença de compostos inibidores do enraizamento provindos da área foliar (ASSIS e TEIXEIRA, 1998). Isto se deve ao fato de as estacas inicialmente não possuírem raízes para absorver água, mas realizarem o processo de evapotranspiração pelas folhas (HARTMANN et al., 2002; TCHOUNDJEU et al., 2002). Para minimizar estes efeitos é fundamental a utilização de um ambiente adequado à manutenção das estacas, aliado a estacas com folhas completamente desenvolvidas.

Aproveitar ao máximo a planta matriz fornecedora de material vegetal para a multiplicação por estaquia é fundamental para qualquer viveiro de produção de mudas, sobretudo em coleções onde existem poucas plantas de uma mesma variedade ou somente uma (DE OLIVEIRA et al., 2003). Estacas de cipó-de-são-joão apresentam a distância entre nós suficiente para permitir a confecção de estacas com apenas um nó ou gema, com isso, maximiza-se o número de plantas possíveis de se obter partindo de um determinado número de ramos.

Dessa forma, realizou-se este trabalho com o objetivo de avaliar a influência do número de folíolos e nós no enraizamento de estacas semilenhosas de cipó-de-são-joão.

\section{MATERIAL E MÉTODOS}

O experimento foi conduzido no Laboratório de Biotecnologia em Horticultura do Departamento de Horticultura e Silvicultura da Faculdade de Agronomia da Universidade Federal do Rio Grande do Sul (UFRGS), em Porto Alegre, RS, entre os meses de abril e junho de 2013.

As estacas foram obtidas a partir de ramos semilenhosos intermediários de plantas matrizes de cipó-de-são-joão $(P$. venusta), oriundas da área da Faculdade de Agronomia/ UFRGS. A coleta foi realizada no período da manhã, no mesmo dia de confecção das estacas (02/04/13), e os ramos acondicionados em recipientes contendo água.

As estacas foram confeccionadas com um nó (apical) ou dois nós (basal e apical) e com zero, um ou dois folíolos de folhas adultas. Realizou-se um corte em bisel duplo na extremidade basal, que coincidiu com o nó nas estacas de dois nós e o entrenó nas estacas com um nó, com o objetivo de remover parte do córtex (KÄMPF, 2005). No ápice foi realizado um corte transversal.
As estacas foram acondicionadas em bandejas de poliestireno expandido com 72 células de $110 \mathrm{~cm}^{3}$ cada, preenchidas com substrato de casca de arroz carbonizada umedecida. As bandejas foram mantidas em casa de vegetação, com irrigação intermitente por nebulização, mantendo a umidade relativa do ar no ambiente em torno de $80 \%$.

O delineamento experimental utilizado foi em blocos casualizados, em esquema fatorial 2 (número de nós: um ou dois) x 3 (número de folíolos: zero, um ou dois), com quatro repetições de doze estacas por parcela, totalizando 288 estacas.

Aos 84 dias após a estaquia, foi avaliado o percentual de estacas enraizadas (\%EE), o comprimento de brotações (CB), a massa seca de brotações (MSB), e, por estaca enraizada, a média de número de raízes de primeira ordem (NR), comprimento máximo de cada raiz de primeira ordem (CR), e, volume de raízes (VR) e a massa seca de raízes (MSR).

A medida do comprimento de raízes foi tomada desde a base da estaca, no ponto de inserção de cada raiz de primeira ordem, até a extremidade mais distal, com auxílio de régua. A determinação do volume de raízes foi realizada por diferença de volume, a partir de raízes colocadas no fundo de uma proveta de $20 \mathrm{~mL}$ e adicionado sobre as mesmas $5 \mathrm{~mL}$ de etanol 96\%, de modo a não existirem bolhas de ar. Para a determinação da massa de matéria seca de raízes e brotações (g), estas foram secas em estufa à $65^{\circ} \mathrm{C}$ até a obtenção da massa constante (JUNIOR et al., 2013).

Os resultados foram submetidos à análise de variância e comparados pelo teste de Tukey a $5 \%$ de probabilidade de erro, via modelo misto no software estatístico SAS Enterprise Guide ${ }^{\circledR}$.

\section{RESULTADOS E DISCUSSÃO}

De acordo com a análise de variância, verificou-se que não houve interação significativa entre os fatores de tratamento (número de folíolos e número de nós) para as variáveis: percentual de estacas enraizadas, comprimento de brotações e massa seca de brotações. Para estas variáveis foi observado ainda que é estatisticamente indiferente a confecção de estacas com um ou dois nós (Tabela 1).

Tabela 1. Percentual de estacas enraizadas (\%EE), comprimento de brotações (CB) e massa seca de brotações (MSB) de estacas de cipó-de-são-joão (Pyrostegia venusta (Ker-Gawl.) Miers) em função de diferentes números de nós e folíolos. Table 1. Porcentage of rooted cuttings (\% EE), length of shoots (CB) and dry mass of shoots (MSB) of cuttings of flame vine (Pyrostegia venusta (Ker-Gawl.) Miers) for different numbers of nodes and leaf.

\begin{tabular}{|c|c|c|c|}
\hline Fatores & $\mathbf{\% E E}$ & $\mathbf{C B}(\mathbf{c m})$ & \multicolumn{1}{|c|}{ MSB (g) } \\
\hline 1 nó & $33^{\text {ns }}$ & $2,15^{\text {ns }}$ & $0,057^{\text {ns }}$ \\
\hline 2 nós & 40 & 1,63 & 0,040 \\
\hline 2 folíolo & $0 \mathrm{c}^{*}$ & $0,51 \mathrm{c}^{*}$ & $0,009 \mathrm{~b}^{*}$ \\
\hline 1 folíolo & $45 \mathrm{~b}$ & $1,80 \mathrm{~b}$ & $0,043 \mathrm{~b}$ \\
\hline 2 folíolos & $66 \mathrm{a}$ & $3,37 \mathrm{a}$ & $0,092 \mathrm{a}$ \\
\hline C.V $(\%)$ & 42,67 & 47,93 & 72,15 \\
\hline
\end{tabular}

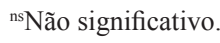

"Médias seguidas de letras distintas, na coluna, diferem significativamente entre si pelo teste de Tukey ao nível de $5 \%$ de probabilidade de erro. 
A possibilidade de confecção de estacas com apenas um nó é interessante, pois permite a produção do dobro de estacas por planta matriz, o que é fundamental quando a disponibilidade das mesmas é limitada (PAIVA et al., 1999), além de diminuir o volume de material propagativo a ser transportado e manuseado (LIMA et al., 2010).

Para o fator número de folíolos, ocorreu o aumento no percentual de enraizamento em estacas com mais folíolos (66\%) como verificado por Vignolo et al. (2014) e Heintze et al. (2015), e o não enraizamento das estacas sem folíolos. Assim, a presença de folhas nas estacas confirma o papel chave destas para a formação do novo sistema radicular, sendo responsável pela produção de assimilados e de substâncias como auxinas, sendo esta última sintetizada nesses locais (TAIZ e ZEIGER, 2009).

Foi observado efeito significativo da interação entre número de folíolos e nós para as variáveis: número de raízes (NR), comprimento máximo de cada raiz de primeira ordem (CR), volume de raízes (VR) e massa seca de raízes (MSR) (Tabelas 2 e 3). Estas variáveis são importantes para avaliar a qualidade do sistema radicular, pois após o processo de transplante da muda para o campo, aquelas com maior tamanho e quantidade de raízes são melhores ancoradas ao solo, o que favorece um maior percentual de sobrevivência, além de induzir um desenvolvimento mais rápido e vigoroso das mesmas (REIS et al., 2000).

Tabela 2. Efeito da interação entre número de nós e folíolos no número de raízes (NR) e comprimento máximo de cada raiz de primeira ordem (CR) por estaca enraizada de cipó-de-são-joão (Pyrostegia venusta (Ker-Gawl.) Miers).

Table 2. Effect of the interaction between number of nodes and leaf in the number of roots (NR) and maximum length of each root first order roots (CR) by the vine-rooted cutting of flame vine (Pyrostegia venusta (Ker-Gawl.) Miers).

\begin{tabular}{|c|c|c|c|c|}
\hline & \multicolumn{4}{|c|}{ NR } \\
\hline & 0 folíolo & 1 folíolo & 2 folíolos & C.V $(\%)$ \\
\hline 2 nó & $0,0 \mathrm{~A} \mathrm{~b}^{*}$ & $3,22 \mathrm{~A} \mathrm{a}$ & $3,75 \mathrm{~B} \mathrm{a}$ & 29,11 \\
\hline & $0,0 \mathrm{~A} \mathrm{c}$ & $2,91 \mathrm{~A} \mathrm{~b}$ & $6,77 \mathrm{~A} \mathrm{a}$ & 29,34 \\
\hline & & CR $(\mathrm{cm})$ & \\
\hline & 0 folíolo & 1 folíolo & 2 folíolos & \\
\hline & $0,0 \mathrm{~A} \mathrm{~b}$ & $21,93 \mathrm{~A} \mathrm{a}$ & $26,21 \mathrm{~A} \mathrm{a}$ & 39,10 \\
\hline
\end{tabular}

"Médias seguidas por letras maiúscula distintas na coluna e minúscula distintas na linha, diferem significativamente entre si pelo teste de Tukey ao nível de $5 \%$ de probabilidade de erro.

Tabela 3. Efeito da interação entre número de nós e folíolos no volume de raízes (VR) e massa seca de raízes (MSR) por estaca enraizada de cipó-de-são-joão (Pyrostegia venusta (Ker-Gawl.) Miers).

Table 3. Effect of the interaction between number of nodes and leaf in the root volume (VR) and dry mass of roots (MSR) for rooted cutting of flame vine (Pyrostegia venusta (Ker-Gawl.) Miers).

\begin{tabular}{|c|c|c|c|c|}
\hline & \multicolumn{4}{|c|}{ VR $(\mathrm{mL})$} \\
\hline & 0 folíolo & 1 folíolo & 2 folíolos & C.V $(\%)$ \\
\hline 2 nó & $0,0 \mathrm{~A} \mathrm{~b}^{*}$ & $2,92 \mathrm{~A} \mathrm{a}$ & $3,80 \mathrm{~A} \mathrm{a}$ & 40,92 \\
\hline & $0,0 \mathrm{~A} \mathrm{c}$ & $0,89 \mathrm{~B} \mathrm{~b}$ & $3,45 \mathrm{~A} \mathrm{a}$ \\
\hline & & MSR $(\mathrm{g})$ & & 21,78 \\
\hline & 0 folíolo & 1 folíolo & 2 folíolos & C.V (\%) \\
\hline n nós & $0,0 \mathrm{~A} \mathrm{~b}$ & $0,26 \mathrm{~A} \mathrm{a}$ & $0,33 \mathrm{~A} \mathrm{a}$ & 45,71 \\
\hline
\end{tabular}

*Médias seguidas por letras maiúscula distintas na coluna e minúscula distintas na linha, diferem significativamente entre si pelo teste de Tukey ao nível de $5 \%$ de probabilidade de erro.

Independente do número de nós nas estacas, aquelas com ausência de folíolos, por não terem enraizado, apresentaram valores iguais a zero para NR, CR, VR e MSR, diferindo estatisticamente das estacas com um ou dois folíolos (Tabelas 2 e 3). Ou seja, a presença de folíolos favoreceu o enraizamento e a qualidade do sistema radicular, corroborando com os resultados obtidos por Sousa et al. (2014) e Silva et al. (2015).

Já ao comparar-se a presença de um ou dois folíolos, observou-se que nas estacas com dois nós, houve maior
NR, CR, VL e MSR com dois folíolos em relação àquelas com um (Tabelas 2 e 3). De acordo com Del Rio e Caballero (1991), durante o enraizamento, a base das estacas apresenta um forte dreno de hidratos de carbono; dessa forma, o número de nós reflete a quantidade de reservas a serem utilizadas durante este processo e por isso, estacas menores, com um nó, tendem a apresentar um sistema radicular não satisfatório. Associado a isso, o maior número de folhas favorece a emissão de raízes pela indução do balanço favorável de auxinas (MOUBAYIDIN et al. 2010). 
Além da presença de nós e folíolos, outros fatores podem estar envolvidos no processo de enraizamento, tais como a idade dos tecidos utilizados, reservas contidas, balanço hormonal nos tecidos, sensibilidade celular, presença de outras moléculas nos tecidos e condições nutricionais e fitossanitárias da planta matriz (SILVA et al. 2015).

\section{CONCLUSÃO}

A propagação de cipó-de-são-joão é eficiente através do uso de estacas semilenhosas, contendo dois nós e dois folíolos, mantidas em casa de vegetação sob nebulização intermitente.

\section{AGRADECIMENTOS}

Os autores agradecem a FAPERGS e ao CNPq pelo auxílio financeiro.

\section{REFERÊNCIAS}

ASSIS, T.A.; TEIXEIRA, S.L. Enraizamento de plantas lenhosas. TORRES, A.C.; CALDAS, L.S.; BUSO, J.A. Cultura de tecidos e transformação genética de plantas. Brasília: Embrapa, 1998. p.261-297.

DE OLIVEIRA, A.F.; PASQUAL, M.; CHALFUN, N.N.J.; REGINA, M.A.; RINCÓN, C.D.R. Influência do número de nós em estacas semilenhosas de oliveira (Oleaeuropaea L.) no enraizamento sob câmara de nebulização. Ciência e Agrotecnologia, Lavras, v.27, n.2, p.332-338, 2003. DOI: http://dx.doi.org/10.1590/S1413-70542003000200012.

DEL RIO, C.; CABALLERO, J.M. Effects of carbohydrate content on the seasonal rooting of vegetive and reproductive cuttings of olive. Journal of Horticultural Science, Ashford, v.66, n.3, p.301-309, 1991.

FACHINELLO, J.C.; HOFFMANN, A.; NACHTIGAL, J.C.; KERSTEN, E.; FORTES, G.R.L. Propagação de plantas frutíferas de clima temperado. 2.ed. Pelotas: UFPEL, 1995. 178p.

FACHINELLO, J.C.; HOFFMANN, A.; NACHTIGAL, J.C. Propagação de plantas frutíferas. Brasília: Embrapa Informação Tecnológica, 2005. 221p.

HARTMANN, H.T.; KESTER, D.E.; DAVIES JUNIOR, F.T.; GENEVE, R.L. Plant propagation: principles and practices. 7.ed. New Jersey: Prentice Hall, 2002. 880p.

HEINTZE, W.; PETRY, H.B.; SCHWARZ, S.F.; DE SOUZA, P.V.; SCHAFER, G. Propagação de Thunbergia mysorensis (Wight) por estaquia. Ciência Rural, Santa Maria, v.45, n.8, p.1455-1458, 2015. DOI: http://dx.doi. org/10.1590/0103-8478cr20140764.
JUNIOR, C.L.A.; DANNER, M.A.; KANIS, L.A.; DESCHAMPS, C.; ZANETTE, F. Enraizamento de estacas semilenhosas de maracujazeiro amarelo (Passiflora actinia Hook). Semina: Ciências Agrárias, Londrina, v.34, n.6, p.3663-3668, 2013. DOI: http://dx.doi.org/10.5433/16790359.2013v34n6Supl1p3663.

KÄMPF, A.N. Produção comercial de plantas ornamentais. 2.ed. Guaiba: Agrolivros, 2005. 256p.

LIMA, R.L.S.; SEVERINO, L.S.; PEREIRA, W.E.; LUCENA, A.M.A.; GHEYI, H.R.; ARRIEL, N.H.C. Comprimento das estacas e parte do ramo para a formação de mudas de pinhão-manso. Revista Brasileira de Engenharia Agrícola e Ambiental, Campina Grande, v.14, n.11, p.1234-1239, 2010. DOI: http://dx.doi.org/10.1590/ S1415-43662010001100014.

LOHMANN, L.G. Bignoniaceae in Lista de Espécies da Flora do Brasil. Rio de Janeiro: Jardim Botânico do Rio de Janeiro. Disponível em: <http://floradobrasil.jbrj. gov.br/jabot/floradobrasil/FB113866>. Acesso em: 09 de outubro de 2015.

LORENZI, H.; SOUZA, H.M. Plantas Ornamentais no Brasil: arbustivas, herbáceas e trepadeiras. Nova Odessa: Instituto Plantarum, 1999. 1088p.

MOUBAYIDIN, L.; PERILLI, S.; DELLO LOIO, R.; DI MAMBRO, R.; COSTANTINO, P.; SABATINI, S. The rate of cell differentiation controls the Arabidopsis root meristem growth phase. Current Biology, Cambridge, v.20, n.12, p.1138-1143, 2010. DOI: http://dx.doi. org/10.1016/j.cub.2010.05.035.

OSTERC, G.; ŠTAMPAR, F. Differences in endo/exogenous auxin profile in cuttings of different physiological ages. Journal of Plant Physiology, Rockville, v.168, p.2088-2092, 2011. DOI: http://dx.doi.org/10.1016/j.jplph.2011.06.016.

PAIVA, J.R.; PAIVA, W.O.; CORDEIRO, E.R.; SABRY NETO, H. Parâmetros genéticos em progênies de polinização livre de acerola. Pesquisa Agropecuária Brasileira, Brasília, v.34, n.4, p.629-634, 1999. DOI: http://dx.doi.org/10.1590/S0100-204X1999000400014.

REIS, J.M.R.; CHALFUN, N.N.J.; LIMA, L.C.O.; LIMA, L.C. Efeito do estiolamento e do ácido indolbutírico no enraizamento de estacas do porta-enxerto Pyrus calleryana Dcne. Ciência e Agrotecnologia, Lavras, v.24, n.4, p.931938, 2000.

SILVA, A.S.; REGES, N.P.R.; DE MELO, J.K.; DOS SANTOS, M.P.; SOUSA, C.M. Enraizamento de estacas caulinares de ixora. Advances in Ornamental Horticulture and Landscaping, Campinas, v.21, n.2, 
p.201-208, 2015. DOI: http://dx.doi.org/10.14295/aohl. v21i2.656.

SOUSA, C.M; SANTOS, M.P; CARVALHO, B.M. Enraizamento de estacas de maracujazeiro-doce (Passiflora alata Curtis). Científica, Jaboticabal, v.42, n.1, p.68-73, 2014. DOI: http://dx.doi.org/10.15361/1984$5529.2014 \mathrm{v} 42 \mathrm{n} 1 \mathrm{p} 68-73$.

TAIZ, L.; ZEIGER, E. Fisiologia vegetal. 3.ed. Porto Alegre: Artmed, 2009. 719p.

TCHOUNDJEU, Z.; AVANA, M.L.; LEAKEY, R.R.B.; SIMONS, A.J.; ASAAH, E.; DUGUMA, B.; BELL, J.M. Vegetative propagation of Prunus africana: effects of rooting medium, auxin concentrations and leaf area. Agroforestry Systems, The Netherllands, v.54, p.183-192, 2002. DOI: http://dx.doi.org/10.1023/A:1016049004139.

UBEDA-TOMÁS, S., BEEMSTER, G.T., BENNETT, M.J. Hormonal regulation of root growth: integrating local activities into global behavior. Trends in Plant Science, Londres, v.17, n.6, p.326-331, 2012.

VIGNOLO, G.K.; PICOLOTTO, L.; GONÇALVES, M.A.; PEREIRA, I.S.; ANTUNES, L.E.C. Presença de folhas no enraizamento de estacas de amoreira-preta. Ciência Rural, Santa Maria, v.44, n.3, p.467-472, 2014. DOI: http://dx.doi. org/10.1590/S0103-84782014000300013. 
